\title{
Ecological, modular and affordable housing
}

\author{
J. Quale \\ University of Virginia School of Architecture, USA
}

\begin{abstract}
Modular and panelized construction techniques have the potential of significantly reducing environmental impact - although much of that potential is unrealized among prefab homebuilders in the United States today. The ecoMOD project at the University of Virginia School of Architecture is intended to create a series of ecological, modular and affordable house prototypes. The goal is to demonstrate the environmental potential of prefabrication, and to challenge the modular and manufactured housing industry in the U.S. to explore this potential. In the context of this research and design/build project, an interdisciplinary group of architecture, engineering, landscape architecture, business, environmental science, planning and economics students are participating in the design, construction and evaluation phases of the project. The project is imbedded in the curriculum of the university.

Working with non-profit affordable housing organizations, the built homes will be sold to low-income families with subsidies for down payments and financing. The first completed house is currently being evaluated as part of a process to determine the environmental impact of the homes during their life cycle; perceptions of the homes by the owners and neighbors; the energy efficiency of the design and equipment; the feasibility of their transfer to the modular housing industry; the life cycle costs; and the financial viability of taking the prototypes into production. The results of the evaluations will influence later designs, and the evaluation methods and recommendations will be made publicly available. The project is mostly funded, and will continue through to 2010 at a minimum.

Keywords: prefabricated construction, modular housing, panelized construction, environmental impact, affordable housing, student design / build, post occupancy evaluation, life cycle assessment, energy efficient buildings, structural insulated panels.
\end{abstract}




\section{Introduction}

Centralized within a climate-controlled facility, prefabricated residential construction offers material and transportation efficiencies, as well as opportunities for stricter quality control. Although several U.S. companies have developed EnergyStar-rated models (a program organized by the U.S. Environmental Protection Agency to encourage energy efficiency), and some sell quality homes superior to conventional stick-built construction, few are seriously looking at the environmental impact of their methods or materials.

From a design viewpoint, despite the popularity of modern prefab homes in Dwell Magazine and other mainstream media outlets, very few manufacturers offer quality contemporary design. The vast majority offer standardized designs with open interiors, and exterior skins composed of elements borrowed from late $19^{\text {th }}$ and early $20^{\text {th }}$ century home styles.

Among the most surprising trends in prefab housing is the growth in the upper end of the market. Whereas the public perception is that prefabricated homes are an inferior product and only appropriate for the least affluent, increasingly upscale builders are recognizing the financial and logistical advantages of centralized fabrication [1]. Although they seldom emphasize the prefab nature of the construction, major U.S. homebuilders such as the Pulte and Toll Brothers are transitioning from site built to pre-built for their middle and upper-middle market rate houses [2]. Pejoratively referred to as "MacMansions," the percentage of these that are fully prefabricated homes is still small. Yet major homebuilders clearly recognize the future is in prefab, which can typically offer a more predictable product, with more control over quality, schedule and price. Pulte recently built a panelized prefab plant in Northern Virginia, called "Pulte Home Science" (PHS) where they fabricate structural insulated wall panels, roof trusses and precast foundation systems. They are able to 'dry-in' a home is a fraction of the time it takes them to build one on site, and their PHS homes now account for roughly $20 \%$ of their single family home market [3].

Yet the benefits of these investments are not trickling down to the lower end of the market. Manufactured housing, the technical term for transportable trailers built to the U.S. Department of Housing and Urban Development (HUD) building code, is still the least expensive way of getting into the new housing market. While the HUD code has gotten more restrictive in recent years - with tighter guidelines for insulation and the attachment of the trailers to foundations - the fact remains that manufactured houses are still inferior products. They are difficult to finance, built with the cheapest possible materials, and like an automobile, tend to depreciate in value. In contrast with HUD code homes, prefabricated homes that use modular, panelized or component prefab elements are built to code of the local jurisdiction. While this requires manufacturers to devise creative ways to track the correct code requirements for a given home going down their assembly line, many states and municipalities in the U.S. have recently or are about to adopt the International Residential Code. Unlike HUD code houses, these homes are considered 
permanent construction, and do not face financing problems, and therefore tend to appreciate in value in the same way as a site built house.

The general public is not sophisticated enough to recognize the difference between manufactured homes and better quality modular or panelized prefab homes. So its not surprising the Pulte doesn't market their prefab homes any differently than their stick built. In fact, Pulte is literally replicating the same models in their PHS facility that they build on site. It is likely that most of the owners of those models don't know about the prefab nature of the construction.

The availability of affordable housing in the U.S. is a growing problem. As construction costs increase and home values continue to grow, the challenge of buying a home in many markets is becoming insurmountable for many. House values have increased $20 \%$ in just the last two years, while incomes for middle and lower class Americans have remained flat [4]. A family that chooses to buy a manufactured house is typically restricted to placing that house on a suburban site, where land is cheaper. In addition, manufactured houses are designed for the width and orientation of suburban lots, fig. 1. No major manufactured home company offers models designed for urban lots with the entry side facing the street. In addition, the typical single-wide module for these homes measures $12^{\prime}-0$ " to 14 '-0" wide by $48^{\prime}-0$ " long - a size nearly impossible to transport into most tight urban areas. By default, families in the affordable housing market are being pushed to the periphery, where they have to take on the added financial burden of driving everywhere.

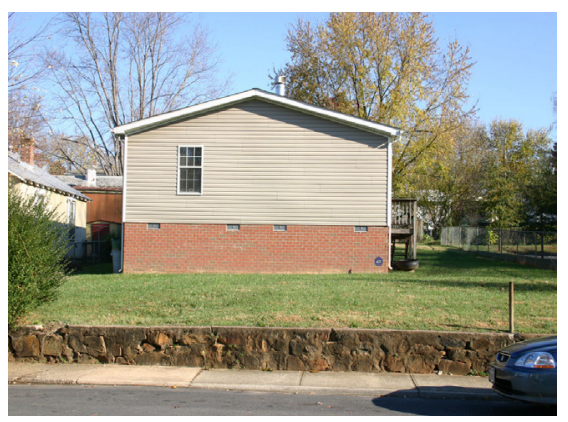

Figure 1: $\quad$ Standard modular house in urban setting; note entrance on right.

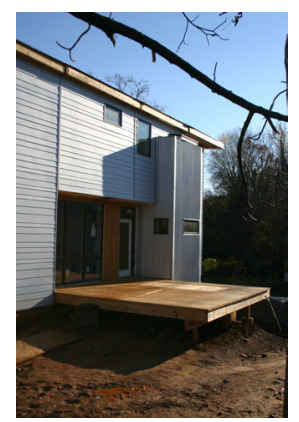

$\begin{array}{ll}\text { Figure 2: } & \begin{array}{l}\text { Entry deck of } \\ \text { ecoMOD1 house under } \\ \text { construction. }\end{array}\end{array}$

\section{Goals of project}

It is in this context that the ecoMOD project was developed. ecoMOD is a collaborative research and design / build project at the University of Virginia School of Architecture focused on creating well designed and well-built homes that cost less to live in, minimize damage to the environment, and appreciate in value. The goal of ecoMOD is to create a series of proto-typical ecological and modular houses for low-income families in central Virginia. Over the next 
several years, UVA architecture, engineering, landscape architecture, business, environmental science, planning and economics students and faculty will provide a minimum of four prefabricated houses. Through partnerships with Piedmont Housing Alliance (PHA) of Charlottesville, Virginia and Habitat for Humanity of Greater Charlottesville (HFHGC), the homes will be placed in established communities. PHA will sell three of the homes to low-income families in the Piedmont region with down payment and financing assistance.

The first PHA house, called the OUTin house, fig. 2, was designed, prefabricated off-site, and sited in the Fifeville neighborhood of Charlottesville on $71 / 2$ Street. It is being sold as a two-unit condominium (basement unit sold separately from the upper two floors), and includes a rainwater collection system that delivers potable water, an extremely energy efficient construction system, a solar hot water collector, and landscape of native, drought tolerant plants.

ecoMOD2 - known as the preHAB house - is a panelized design that will house a family displaced by Hurricane Katrina. Constructed in partnership with HFHGC and the HFH affiliate in Jackson County, Mississippi, the design is intended to demonstrate the potential of prefab for Habitat affiliates. HFH is already pursuing panelized construction with their "Operation Home Delivery" project focused on delivering wall panels from around the country to be set up in the hurricane devastated Gulf Coast region. The goal with the preHAB house is to take this one step further, by designing a home that can be pre-fabricated in various ways - panels, room-sized modules, and/or smaller components. Typically, HFH affiliates use conventional wood framing or 'stick-built' strategies with a large, often inexperienced volunteer work force. The future homeowners are usually required to put some 'sweat equity' into their home, and while they purchase the home, the price is significantly lower than the cost of the home.

With ecoMOD2, we imagine future disaster relief efforts where $\mathrm{HFH}$ affiliates from around the U.S. could use their volunteers to build house panels or modules or components without taking too much time or money away from their own local building efforts. The perception among Habitat officials is that prefab construction conflicts with HFH's volunteer labor strategies. These officials see the value in the dramatic scene of a crowd of volunteers hammering conventional walls together to energize the community and maximize fundraising opportunities. Yet with a carefully designed prefab house system, $\mathrm{HFH}$ affiliates from across the country could also contribute to a larger effort. By offering choices for the scale of their involvement, the preHAB house strategy could include smaller affiliates without the resources to ship a complete home to a disaster area.

The shipping distance is another factor to consider with prefabricated components. In the context of Hurricane Katrina, HFH affiliates in the states adjoining Mississippi and Louisiana could contribute modules. HFH affiliates within 500 miles could produce wall and roof panels, and others could ship smaller and simpler components. This idea can be likened to the way thousands of Americans prepared first-aid dressings in their homes for injured soldiers during World War I. With more than 200,000 homes destroyed by hurricanes in 2005 , the Gulf Coast is in the early stages of a long rebuilding effort. 
This first preHAB house will be sited on an empty lot in a 1960's affordable housing subdivision in the city of Gautier, Mississippi.

Design will begin in Fall 2006 on ecoMOD3 for a low-income family in the Charlottesville area. Partnering again with PHA, two project options are being considered. One possibility is to rehabilitate and add a modular unit to a tiny historic home, believed to have been built in the 1880's by a freed slave in Charlottesville. The modest house is in a serious state of disrepair, and was slated for demolition. Historic preservation students would participate in the design phase, along with architecture, engineering and landscape architecture students. The other option is to produce a small multi-unit elderly housing complex. In this scenario, the shell of the units - the modules - would be prefabricated by a modular manufacturer, with the students providing the design, and building the smaller scale modules and components.

Each completed house is to be monitored and evaluated carefully, with the results guiding the designs of subsequent houses. The evaluation process occurs in two overlapping courses with additional participation from students and faculty from non-design disciplines such as business, environmental science, economics and planning.

\section{Design phase}

The design process for the ecoMOD homes is structured to maximize the educational possibilities of the project. The project is imbedded in the curriculum of the University, and the coursework has been recognized by professional organizations and major media outlets for its' innovative pedagogy [5]. A series of mixed graduate and undergraduate design studios in the School of Architecture, combined with independent study and thesis students from the University's School of Engineering and Applied Science, form the core of the design process. The two-year cycle includes an academic year for design, followed by a summer of construction, and an academic year of evaluation.

The studios are collaborative and interdisciplinary, and they include architecture, landscape architecture, and potentially historic preservation students. The engineers meet regularly with the rest of the team, but also have their own coursework.

The first design studio for ecoMOD1 began with student presentations on relevant prefab and ecological case studies, and design studies that address specific activities within the home. The team collaborated in small groups, and the groups were regularly shuffled in order to minimize the potential of isolated subgroups. Landscape architecture students worked along side architecture students, and were often participating in the same assignments. The University of Virginia architecture and landscape architecture programs were combined into a single department in 2004, and a significant percentage of graduate students participate in dual degree programs between two of the four disciplines in the school - architecture, landscape architecture, urban and environmental planning, and architectural history.

Participants in the first studio were paired with planning students for an analysis project on the neighborhood for the first house - Fifeville, a 
traditionally African-American neighborhood. A neighborhood development workshop taught by a planning professor offered the context for this collaboration. Although the students welcomed the possibility of interdisciplinary work, the results of analysis did not live up to the faculty's expectations. Analysis of urban context takes on very different forms in the two disciplines, and the students found it difficult to collaborate within their interdisciplinary sub-groups. The students probably required a clearer introduction into the values supporting their discipline's distinct worldviews, to create a more open-minded environment. The Project Director will do the assignment again, but with more clearly defined introductions.

However, one of the most positive aspects of the early collaboration with the planning students was the ensuing discussion about the broader agenda for the project. Planning students were asked to frame a set of guidelines for decisionmaking during the design process. Most participants were surprised that the lists prepared by the planning students overlapped with the collaborative list developed by the architecture and landscape architecture students. However, one planning student subgroup posited that the design ought to replicate the existing architectural language of the neighborhood. A heated discussion on this topic helped all parties better understand and articulate their positions. It also led to a self-imposed commitment by the designers to present their design ideas to members of the Fifeville Neighborhood Association (FNA). Intended as a way to receive feedback about their preliminary design ideas, the meetings with FNA became an essential part of the design process. The students thought some of their design ideas might not align with the opinions of the FNA membership, but they found they were not so far apart. The participants in the feedback sessions (four sessions over a period of six months) never questioned the contemporary nature of the designs, and mostly responded to functional issues. The most heated discussion in the FNA meetings related to the appropriate location for the kitchen - nearest the street or nearest the backyard. Eventually the designers found an effective middle ground, with the kitchen in the middle and a clear line of sight to both the street and the backyard.

The students also interacted regularly with professional members of the local community - from building department officials to local contractors and consultants.

A team of student managers working with the faculty Project Director collectively made important design decisions. Decisions that required a comparison of multiple possibilities were often documented with a six pointed decision web - a concept adapted from the professional world. The web required the team to remember that decisions are a careful balancing of aesthetic, technical, financial, social and ecological issues - with the sixth point being an overall score. In concept, the webs were meant to facilitate the decision process, but in reality, the webs more mostly treated as a documentation of a decision. The students were not enthusiastic about the decision webs at the time, but now appreciate the graphic representations of their collective thinking.

During the break between the two design studios, the client decided to change the site, forcing the team to respond to a complex challenge. The students set about redesigning the house for the new narrower lot. The change 
significantly delayed the development of the design, but forced the team to address the adaptability of the design to various sites. The challenge was repeated again two weeks before the end of the spring semester, as the team was headed into the construction phase. A series of events led to another site change - still in the Fifeville neighborhood - but a site with a different solar orientation, topography and urban context. Once again, the design had to change, and the schedule was delayed. As with the first site change, the design team responded by exploring the ways the design could be more easily sited on various topographies, and in various microclimates.

\section{Build phase}

The start of the construction process for ecoMOD1 was delayed by nearly two months. The students fabricated eight small modules for the two-story house in a decommissioned airport hangar owned by the university, and transported them to the infill site, fig. 3. Unlike conventional modular houses, the students designed their modules to fit the proportion of urban infill sites, and to be easily transported along narrow streets. The modules were less than half the size of a typical module, allowing for the use of a less expensive crane, and the possibility of moving the modules to the narrowest streets with the tightest turning radiuses.

The majority of the design studio students elected to stay in town after their graduation, and participate in the construction process, fig. 4. Most of them had little or no building experience. The team worked through all the logistics themselves, including coordination between various building trades, material procurement, and transportation. They also built the entire of the house, with the exception of the basement / foundation, and the final installation of the plumbing, electrical and mechanical infrastructure. Students worked with professionals for each of these scopes of work, but could not be held responsible for the permitting process.

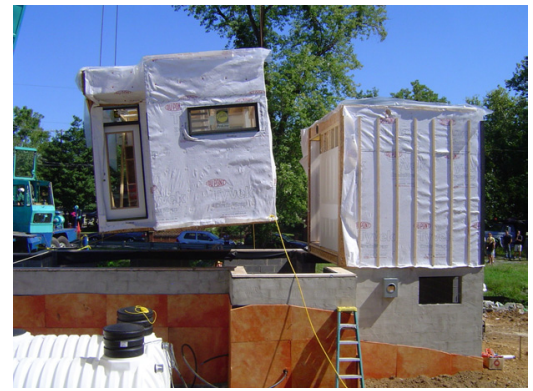

Figure 3: Second of eight modules lowered on basement / foundation.

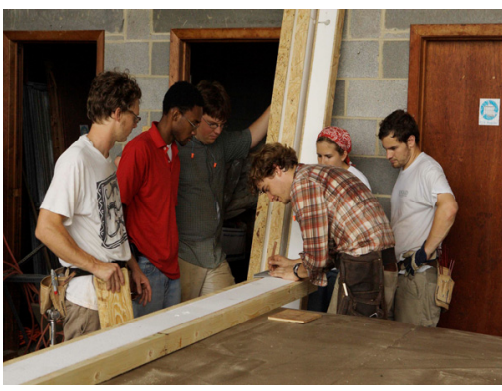

Figure 4:

Construction preparing insulated roof joist.

Visits to a few modular house fabrication facilities confirmed that the required tool and equipment where within our budget. The funding for the tools, 
and a significant percentage of the summer student fellowship money was provided by a local non-profit funding organization. The remainder of the funding was raised the Project Director via grants and donations. The students devised strategies to work around the more sophisticated equipment that was beyond our reach financially. For example, one company uses pneumatic devices to allow the modules to 'hover' as they move along the assembly line. The students built the eight modules in a single line in the hangar, and only moved them when it was time to transport them at the end. For this, they designed and fabricated a set of 'house skates' using left over framing material on wheels to roll the modules over a trailer, where they were lowered on to the bed. Conventional jacks were used to lift the house, and three or four people easily pushed the modules while on the "skates."

\section{Evaluation phase}

Each completed house is to be monitored and evaluated carefully, with the results guiding the designs of subsequent houses. The evaluation process occurs in two overlapping courses with participation from students and faculty from architecture, engineering, commerce, business, environmental science, landscape architecture and planning. As of this writing, the evaluation is appropriately $50 \%$ complete, with a more thorough analysis available in late spring 2006.

The ecoMOD1 evaluation team of students is looking carefully at the choices made by the design / build team. This includes the following: 1) monitoring the energy efficiency and water use of the house, contrasting the data with simulations and comparable homes 2) thorough life-cycle assessments of the materials and construction process 3) a post-occupancy evaluation with the eventual homeowners, including questions about thermal and lighting comfort, as well as evaluation of the design hypotheses set out in the design phase 4) an affordability analysis comparing the cost of both the prototype and the eventual production model to other available modular homes 5) a cost/benefit analysis and investigation of the design's suitability for production with a major manufacturer, and 6) a summing up of the key recommendations, including a prioritized list of issues for the next design / build team to consider.

Preliminary conclusions indicate the following: 1) while the potable rainwater collection system will save the homeowners money and reduce the home's environmental impact, the cost of the filtration equipment negates the efficacy of recommending it for city locations where the municipal water supply is relatively inexpensive 2) stricter guidelines need to be established to make sure the emphasis on building material efficiency at the hangar during the off-site construction process is not lost during the final phase on site, where a dumpster was available 3) while the design adequately addresses shading from the summer sun, it does not appear to sufficiently address the potential positive contribution of solar heat gain during the winter months 4) the material life cycle assessments so far support the design decisions, but additional research is required into a comparison of the cementitious lap siding (as selected for ecoMOD1) versus the more conventional choice of vinyl siding; as well as corrugated galvalume 
roofing versus a membrane or asphalt shingle roof 5) the centralized air handler and ductwork - located in the middle of the conditioned space appears to contribute to the energy efficiency of the mechanical system 6) the combined effect of the energy efficient wall and roof system (structural insulated panels), the equipment and the passive design strategies seem to indicate a minimum of a $40 \%$ reduction in energy costs for the homeowners and 7) the preliminary financial analysis indicates that if the ecoMOD project were a for-profit business venture, it would be able to successfully find its niche in the largely unserved market for ecological, prefabricated and affordable housing.

One other significant consideration is PHA's policy to always sell homes at their appraised value, as a part of their commitment to build wealth in the community. This means they need to raise funds to subsidize the down payments and financing on the homes, to make them available to families between 40 and $80 \%$ of the area median income (PHA's target market). HFH and other organizations tend to ignore the appraised value, and sell the home for as little as they can bear.

This policy contributes to the growing recognition at PHA that single-family affordable homes are no longer a viable option in the Charlottesville area. With house prices and construction costs skyrocketing in the last four years, PHA is increasingly looking to single-family home renovation, and multi-family complexes. The ecoMOD1 house appraised $\$ 40,000$ higher than comparable homes built by PHA, despite the fact that the costs per square foot were the same or lower than these homes. Therefore measures need to be established to minimize the appraised value of the house - at least at the time of the initial appraisal. The appraiser indicated that a significant percentage of that additional appraised value was related to the generous exterior decks.

The architectural and financial evaluation will be complete in May of 2006, and the building monitoring and performance evaluation will be complete one year after the homeowner(s) moves into the space(s).

\section{Conclusions}

The copyright registration process has begun for the design of ecoMOD1, including four adaptations to various solar orientations and topographies. At a minimum, the design drawings for ecoMOD1 and ecoMOD2 will be available for purchase by the summer 2006. The designs will be marketed to affordable housing organizations throughout the mid-Atlantic region, and the ecoMOD team will soon thereafter begin the process of speaking with modular builders about taking some of the designs into production.

The most significant impact of this project has yet to be evaluated specifically the degree to which this form of reality-based service learning contributes positively to the professional lives of the students. The results of that evaluation will reveal themselves over the course of many years. As of this writing, one former student is on her way to Sri Lanka to participate in the postTsunami rebuilding effort as a United Nations employee, and another is designing affordable housing for a large corporate architecture firm.

For further information, the ecoMOD website is www.ecomod.virginia.edu. 


\section{References}

[1] Traynor, T., AB Exclusive State of the Industry Report for 2005: Total Housing Up 7\% to 2.88 Million Units. Automated Builder, pp. 8-9, January 2006.

[2] Kelley, S. P., personal communication, April 2005, Project Engineer, Pulte Home Science.

[3] Holtzman, J., Assembly Required: Builders push the productivity envelope with greater attention to sub-assembly techniques. Big Builder Magazine, November 2004, www.bigbuilderonline.com/Industry-news; and similar figures from personal communication in reference [2] above.

[4] Paycheck to Paycheck: Wages and the Cost of Housing in America; study published by the National Housing Conference, August 2005, www.nhc.org/chp/p2p/.

[5] Taylor, E., AIA Recognizes Ecoliteracy in Architecture Schools, Environmental Building News, July 2005; Global Challenges, CNN International, segment on ecoMOD broadcast several times in November and December 2005; Cox, S., Design, Build, and Repeat, Architectural Record, page 54, November, 2005. 